\title{
UNIVERSALISMO Y PARTICULARISMO EN LA ÉTICA DE KANT ${ }^{*}$
}

\author{
Julio De Zan ${ }^{* *}$ \\ UNER-UNSAM-CONICET
}

\section{Introducción}

La filosofia moderna y contemporánea se ha tenido que enfrentar con el problema de la fundamentación de la Ética y de normas morales de la convivencia que puedan sostener una pretensión de validez independiente de las divergencias axiológicas y de las diferencias de las formas de vida que se desarrollan en sociedades abiertas, pluralistas y multiculturales, en las que solamente se reconocen formas de legitimación postconvencionales. Se trata de fundamentar unos principios que permitan orientar racionalmente también a los propios sentimientos morales. Porque si bien es cierto que no existe moral sin sentimientos, también hay que tener en cuenta que los sentimientos se vinculan a convicciones y actitudes que es preciso esclarecer o iluminar y rectificar mediante la razón. Es necesario además poder juzgar críticamente valores y normas de la eticidad social vigente y del derecho positivo.

El positivismo no ha tenido en cuenta, o no ha podido dar cuenta de esta diferencia entre la "ética" positiva y la moral crítica. Una "ética" que se atenga solamente al criterio de la sanción social, y se oriente por los sentimientos, sigue siendo una "ética" positiva, funcional a los valores y los fines de hecho vigentes en una determinada sociedad, los cuales están siempre condicionados por los intereses y las relaciones de poder imperantes, y no puede alcanzar el valor de una moral autónoma y crítica. Por otro lado, la "fuerza" y estabilidad de los sentimientos para motivar las

\footnotetext{
* Ese artículo es una nueva versión (corregida y aumentada) de la conferencia leída en el Simposio Internacional sobre, "Actualidad de Kant" (en conmemoración de los 200 años de su muerte), Universidad de Salamanca, octubre de 2004, por aparecer en Actas: Kant. Razón y Experiencia, Salamanca, 2005.

**Investigador del CONICET y Profesor Ordinario en las Universidades Nacionales de Entre Ríos (Paraná) y de Gral. San Martín (Buenos Aires); jdezan@arnet.com.ar
} 
acciones y las conductas depende de su retroalimentación a partir de valores fuertes y convicciones compartidas que configuran identidades sociales del tipo de las comunidades tradicionales. En los espacios públicos de la sociedad moderna, fragmentada y colonizada por la racionalidad instrumental y estratégica, estos respaldos, o recursos culturales de sentido y validez, son cada vez más escasos.

Ya en los comienzos de la sociedad y del Estado moderno, como consecuencia de la ruptura de la unidad religiosa del mundo occidental y de las largas décadas de las guerras de religión que habían desangrado y empobrecido a Europa, grandes filósofos como Hobbes, Locke, Espinosa y Rousseau, recurrieron a la figura del pacto social como vía de legitimación de la autoridad política y del derecho a partir de la libre voluntad de los propios individuos. Kant por su parte, aunque adopta y reformula la teoría del contrato social en su filosofía política y del derecho, plantea sin embargo una nueva vía, diferente y paradigmática en el pensamiento ético. La situación con la que se enfrentó Kant en la Ética era la misma con la que se había enfrentado la filosofía del derecho y la teoría política de los contractualistas clásicos: cómo fundamentar normas iguales para todos en una sociedad que ya no puede apelar sencillamente a una tradición cultural y religiosa homogénea, porque estas tradiciones están divididas, se hallan erosionadas y debilitadas, o han sido abandonadas en el proceso de la modernización. Pero Kant trabaja con una diferenciación tajante entre el orden jurídico político y la moralidad. En esta última dimensión su respuesta al problema planteado se ubica en otro plano de reflexión trascendental y de universalidad independiente de la eticidad positiva de tipo comunitarista, y también del contractualismo centrado en el autointerés del individuo, que se ofrecen como las alternativas presuntamente rivales. La analítica de la razón pura práctica, desde este otro nivel de pensamiento, que él llama todavía "metafísico", se propone enunciar los principios trascendentales que permiten justificar el juicio moral critico.

Desde Kant y el idealismo alemán se ha puesto reflexivamente en evidencia, como lo ha señalado $\mathrm{H}$. Marcuse en su libro Razón y revolución, que la metafísica es una condición de posibilidad de la libertad de pensamiento y de la crítica. A 200 años de la muerte del filósofo, la cultura y la filosofía contemporánea tienen planteado otra vez en el centro de los debates actuales aquel ya viejo problema. Las concepciones más tradicionalistas concuerdan con los libertinos y con Nietszche en la convicción de que, 
después del derrocamiento de su legitimación religiosa, la moral ha llegado a su fin, y se ha ingresado en la época del crepúsculo del deber. Esta situación se puede experimentar como una liberación y un avance para la expansión afirmativa de la vida; o como una situación de indigencia que torna más difícil la convivencia entre los hombres y plantea nuevos desafíos al pensar en este contexto del nihilismo. Por lo que hace al mero subjetivismo, o el individualismo moral, pese a estar tan difundidos en la práctica, carecen de significado como teorías filosóficas. La Ética no es un asunto meramente privado porque, para decirlo brevemente con Wittgenstein: "uno sólo no puede seguir una regla", y "no puede haber un lenguaje privado".

La renovación contemporánea de la Ética kantiana se propone enfrentar la situación que acabo de describir y responder a las cuestiones planteadas. Esta misma historia que he tratado de evocar muestra sin embargo que, no obstante la pretensión de universalidad de la moral kantiana, esta concepción es también el producto de la evolución de una historia particular, la de la cultura y la filosofía occidental, que ha llegado con la Ilustración al punto de vista moral universalista. Aunque Kant no haya reflexionado sobre ello, y sin desmedro de la originalidad genial de su filosofía, ella es también el resultado del aprendizaje o de la Bildung a la que se ha llegado a través de una cadena de experiencias de conflictividad en el Mundo Occidental. Su pretensión de universalidad tiene que ponerse a prueba ahora de nuevo, y pasar por la confrontación con las convicciones del ethos de las otras culturas en el espacio de la comunidad global cosmopolita que ella misma había soñado de manera visionaria. De tal confrontación y diálogo de las culturas, esta Ética saldrá probablemente enriquecida. Podrá aprender ahora de otras experiencias y valores ajenos. Pero además, en la medida en que su pretensión de validez universal se sostenga, saldrá también seguramente purificada, o despojada del sesgo particular de su contexto de origen en la ilustración europea, es decir, se tornará al mismo tiempo más formal y más universal. En primera instancia hay sin duda una contradicción entre estas dos perspectivas o desafíos mencionados de: ganar una mayor riqueza de contenido y hacerse a su vez más formal y universal. En el nivel de pensamiento del empirismo lógico esto es absurdo, o carece de sentido. Pero de lo que se trata ya en Kant es precisamente de abrirse a un modo de pensar más amplio (eine erweiterte Denkunsgsart), cuya senda él mismo ha señalado. 


\section{Concepciones éticas particularistas}

El contractualismo y el comunitarismo se presentan como las dos teorías rivales más fuertes que se han enfrentado al universalismo del principio de la moralidad kantiana y a los replanteos contemporáneos de esta concepción de la filosofía moral, como el de la ética del discurso.

Algunas teorías contractualistas, como las de J. Rawls, y E. Tugendhat ${ }^{1}$, que no se conforman con el utilitarismo y se ubican en la cercanía del sentido no instrumental de la moralidad kantiana, han creído que, para hacerlo más plausible, se requieren estas dos estrategias: a) depotenciar la fundamentación filosófica trascendental de la moralidad, o desconectarla de sus presuposiciones sistemáticas, que interpretan como una suerte de fe filosófica de alcance limitado al reducido ámbito de los creyentes en este tipo de filosofía; b) recuperar los contenidos fundamentales más atractivos de la ética de Kant y su pretensión de validez universal mediante un procedimiento contractualista de justificación racional.

El contractualismo empirista y antikantiano ha puesto en evidencia en cambio de manera consecuente, a través de autores como David Gauthier ${ }^{2}$, que este procedimiento opera siempre en el marco de una racionalidad instrumental, y solamente puede justificar el respeto de las reglas acordadas entre nosotros (en este sentido se puede mencionar también aquí a R. Rorty). Esta forma de contractualismo no puede justificar el igual trato de todos los

1 Me refiero aquí especialmente al Tugendhat de Problemas de ética (1983), pero también, todavía, aunque de una forma más sofisticada, a su obra principal: Lecciones de Ética (1993), en la que ensaya, de manera más refinada, la misma operación que Rawls había llevado a cabo en El liberalismo politico (1993). (Cfr. J. De Zan, "E. Tugendhat: filosofía analítica y fundamentación de la ética normativa", en Teoria, Revista del Departamento de Filosofía de la Universidad Nacional de Tucumán, 2004, número especial en homenaje al Prof. Dr. Roberto Rojo, p. 159-176.

${ }^{2}$ Gauthier, D., La moral por acuerdo (1986), Gedisa, Barcelona, 1994; también P. Stemmer, Handeln zugunsten anderer, Berlín 2000. Sobre el debate del contractualismo moral, cfr.: Antón Leist $(\mathrm{Hg})$, Moral als Vertrag? Beiträge zum moralischen Kontraktualismus, W. De Gruyter, Berlin, 2003. 
seres humanos, ni está interesada en ello3.

El comunitarismo ha argumentado al mismo tiempo contra las teorías éticas de orientación kantiana y contra los contractualistas, que todas estas concepciones tienden a reducir la moral a lo jurídico y la vacían de sus contenidos "éticos" sustantivos. Conforme a la crítica comunitaria el formalismo de estas teorías priva al sujeto de su identidad, carece de motivaciones fuertes para el obrar moral ("la impotencia del mero deber") y es funcional con el individualismo liberal de la sociedad moderna.

\subsection{La "ética" identitaria de un nosotros}

Las ideas de la vida buena y los modelos de las virtudes de las comunidades premodernas, y de los diferentes grupos humanos que adoptan y renuevan aquellas formas de vida comunitaria, o crean otras comunidades posmodernas como formas de vida alternativas en el contexto plural de la sociedad civil contemporánea, se apoyan en concepciones del mundo y de la vida, en teorías antropológicas, o en creencias metafísico-religiosas, muchas de las cuales se trasmiten con la fuerza de una tradición y conllevan una determinada comprensión del sentido de la existencia humana y de la felicidad. Estos diversos tipos de comunidades disponen de certezas, de valores fuertes, y de modelos de vida para imitar, de los cuales se deriva una normatividad concretista y más o menos rigurosa, o exigente. Pero estas "éticas" comunitarias solamente pueden ofrecer fundamentaciones relativas de sus valores y de sus densos contenidos normativos, porque dependen de esas creencias u opciones existenciales particulares, las cuales mantienen muchas veces desacuerdos fundamentales e irreductibles que las tornan incompatibles entre sí, y que no son compartidas por el resto de los ciudadanos en la sociedad civil moderna. Sin embargo, como lo han hecho ver los filósofos comunitaristas, parece cierto que la mayoría de los individuos (o una buena parte de ellos) buscan y necesitan la contención de alguna trasnochada forma de comunidad. El ethos constitutivo de un nosotros, que identifica a sus miembros, y la "ética" de las comunidades particulares, pueden plantear legítimas pretensiones de reconocimiento y de respeto de su diferencia, pero estas "éticas" no se pueden considerar sin más como

3 Cfr. J. De Zan, La Ética, los derechos y la moral, Fundación Konrad Adenauer, Montevideo, 2004, pp. 88-93. 
universalmente válidas y vinculantes, y no pueden formar parte de "la razón pública" en el sentido de Rawls.

El intuicionismo y el emotivismo de algunas teorías éticas contemporáneas, que se apoyan en los sentimientos morales, o en los consensos sociales más amplios sobre el bien general y los valores, no están en mejores condiciones $y$, en la medida en que se asumen como contextualistas, reconocen las mismas limitaciones que tienen las concepciones tradicionalistas, como la "ética" de un nosotros, o de una comunidad particular, ligada al ethos de una determinada cultura y a sus instituciones, la cual tiene también las mismas dificultades para el distanciamiento crítico frente a sus propias posiciones, o a sus intereses particulares.

Estas "éticas" comunitarias que, en gran formato, cobran la forma del patriotismo de las comunidades, o de los nacionalismos, pueden además no ser morales ${ }^{4}$, en cuanto convalidan muchas veces diversas formas de asimetría, de opresión y de violaciones de los derechos humanos en su interior, así como la guerra o el terrorismo frente a los otros. Después de las horrorosas tragedias que había provocado en la primera mitad del siglo XX, el ethos de los nacionalismos parecía definitivamente desacreditado y abandonado. Pero el final de siglo ha visto un revival temible de exaltados patriotismos, como el de la República imperial, nacionalismos étnicos, o populistas, en Europa y en Latinoamérica, y fundamentalismos religiosos en

${ }^{4}$ Empleo la distinción entre la "ética" (entre comillas) y la moral en el sentido en que la han planteado, con diversos matices, Paul Ricoeur, Jürgen Habermas, y otros autores contemporáneos como $\mathrm{B}$. Williams, en conexión con la redefinición de la diferencia hegeliana de "moralidad y eticidad". Presupongo con la hermenéutica la prioridad de la "ética" en cuanto a los contenidos axiológicos, y con las teorías de inspiración kantiana, la prioridad del punto de vista moral en cuanto a la fundamentación de los principios normativos universales, y del juicio crítico. Sobre la articulación sistemática de esta concepción compleja, cfr.: J. De Zan, La ética, los derechos y la justicia, edic. cit., 2004; sobre el debate de la "ética" y la moral en la Filosofía actual, cfr.: J. De Zan, Panorama de la ética continental contemporánea, Akal, Madrid, 2002. Escribo la palabra "ética" en este sentido especial entre comillas para diferenciarla de la Ética (con mayúscula) como el nombre de la disciplina filosófica que tiene por objeto estas distinciones. 
el Oriente, que amenazan la convivencia pacífica de los pueblos y obstaculizan el trabajo cooperativo frente a los graves problemas morales, de los derechos humanos, económico-sociales, y ecológicos de la humanidad en la época actual.

\subsection{La "ética" de los intereses de los socios}

El contractualismo se presenta como una teoría rival y alternativa frente al comunitarismo, pero es igualmente particularista, como voy a mostrar. Esta otra concepción entiende poder explicar la "ética" de la sociedad civil contemporánea mediante la descripción de un pacto real implícito, que opera en las relaciones sociales normales. La existencia de este acuerdo se explica mediante el hecho de que los individuos, en la medida en que están interesados en las relaciones de intercambio y cooperación con los demás, concuerdan también en el interés de mantener un sistema de reglas cuya aplicación cuente con su asentimiento, siempre que todos los demás se sometan al mismo tiempo a ellas 5 .

En la situación actual de la sociedad civil los individuos y los grupos sólo pueden apelar horizontalmente los unos a los otros, tratando de convencerse que es de interés recíproco de todos el llegar a acuerdos acerca de la regulación normativa de la interacción. En esta relación está claro que sólo pueden ser admitidas "normas simétricas", cuya vigencia pueda ser considerada como "igualmente buena para todos" en un proceso de negociación que concluye en un consenso fáctico, o en una suerte de contrato moral. Lo que se alcanza por esta vía contractualista, o consensualista, no es

${ }^{5}$ Ensayos de fundamentar la moralidad social sobre estas bases podemos encontrar en los autores citados en nota 1 y 2, y en J-L.H. Mackie, Ética. La invención de lo bueno $y$ de lo malo (1977), Gedisa, Barcelona, 2000. Pero cuando se habla de "contractualismo" en la ética contemporánea, hay que distinguir dos concepciones muy diferentes que se suelen englobar bajo esta denominación. Una es la teoría de Rawls, en tanto este autor, y algunos de sus seguidores, piensan en los términos de un contrato celebrado en condiciones ideales de imparcialidad, las cuales han sido diseñadas conforme a una idea intuitiva de justicia que es anterior al contrato y no se deriva de él, sino que proviene de la tradición de la Ética kantiana. La concepción contractualista a la que me quiero referir en este lugar es empirista y prescinde de toda presuposición a priori de tipo kantiano. 
la fundamentación de una pretensión de verdad, sino un acuerdo de voluntades, o la decisión común de aceptar la autorregulación de la interacción, la limitación de las libertades y la delimitación de los espacios de poder. El situar el acuerdo directamente en el plano volitivo del querer, o de la decisión, tiene la ventaja de que ya no es necesaria otra mediación para el pasaje de la teoría ética a la praxis. Los contractualistas argumentan que la "ética" resultante de este proceso de negociación será ciertamente una "ética" mínima y siempre empíricamente revisable, pero esto no la convierte en meramente relativa o débil porque tiene el respaldo de la voluntad común y del control recíproco.

Sin una "ética" social mínima como la que describe el contractualismo, que incluye deberes de respeto a las cláusulas contractuales, de cooperación, de lealtad, etc., no podría funcionar por cierto ninguna sociedad. Como ha sido destacado por muchos autores, hasta una banda de ladrones sólo puede existir y operar si sus miembros son "morales" en este sentido. Toda asociación en torno a determinados intereses comunes tiene que respetar en su interior estas normas, aunque no las observe hacia fuera, en sus relaciones con los no socios, como es el caso de los códigos de "ética" y de las prácticas de autoprotección de los miembros de las asociaciones de tipo corporativo. Es proverbial incluso el rigorismo de la estricta observancia de esta "ética", y la severidad de las sanciones de la deslealtad, o de la infracción de sus códigos, que caracteriza a la mafia. Todos estos tipos de asociación ilícita cultivan incluso alguna forma de estima recíproca, o de relaciones de fraternidad entre sus miembros. Pero en esta concepción no hay motivos para el mantenimiento de las mismas normas en relación con los otros, con quienes no tenemos intereses comunes de intercambio y cooperación. En muchos casos incluso la apertura y el igual tratamiento de los no socios entraría en contradicción con los propios intereses particulares de la corporación. Este tipo de "moral por acuerdo" es cerrada, y sus códigos tienen que permanecer reservados porque los consensos privados entre sus miembros conllevan casi siempre una cláusula implícita, y a veces el juramento explícito del secreto para la autoprotección y el mantenimiento de las apariencias. En cualquier caso, este tipo de "ética" tiene un alcance siempre limitado, carece de razones para fundamentar y motivar la universalizabilidad de sus normas, y no está disponible a la crítica externa de los terceros excluidos del consenso "entre nosotros". En este aspecto, el contractualismo tiene en definitiva las mismas 
limitaciones particularistas que las éticas tradicionales fundadas en los valores y creencias de una cultura particular ${ }^{6}$.

\section{Comunidad "ética" y contrato social en Kant}

Comunidad y contrato son dos figuras reales que responden a propósitos o necesidades humanas diferentes. Ambas conllevan siempre una "ética". Pero esta "ética" puede entrar en conflicto con la moral; y en ningún caso puede ser el fundamento de la moral, ni creo que lo pretenda, salvo en los casos de los fundamentalismos (religioso, o de mercado). La tesis que voy a sostener aquí es que no se puede hacer jugar este tipo de "ética", y las formas de integración social que ellas pueden realizar, como alternativas frente a la moralidad en sentido kantiano. No es correcto contraponer en principio como antitéticos el universalismo de la moralidad kantiana al particularismo de la "ética" comunitaria, ni a la concepción contractualista de la normatividad de la sociedad moderna, porque el propio Kant ha trabajado con estos dos modelos del contrato social y de la comunidad "ética", como articulables en distintos planos, mientras que el principio superior de la moralidad se sitúa en otra dimensión completamente diferente.

\subsection{El contractualismo de Kant}

Para explicar la constitución del orden jurídico-político, o del Estado, se sirve Kant del modelo conceptual hobbesiano del pacto, o contrato social, motivado por el interés de los individuos en la regulación de los conflictos provocados por la arbitrariedad de su propia libertad que produce una situación de total inseguridad ( $\left.M d S, 312-316 ; 144-146^{7}\right)$. El contrato social no tiene sin embargo para Kant el mismo significado que en sus antecesores. No se trata de la narrativa simbólica del origen de la sociedad y

6 Para una exposición más amplia sobre el debate del contractualismo en la Ética, cfr. la bibliografía citada en notas 1 y 2 .

$7 \mathrm{La}$ abreviatura $M d S$ y la primera cifra entre paréntesis remiten Kant, I. Die Metaphisik der Sitten, Akademie Textausgabe 1908, VII; reimpresa en Ed. W. De Gruyter, Berlin 1968, Bd. VI; la segunda cifra remite a la traducción española de A. Cortina y J. Conill: I. Kant, Metafisica de las Costumbres, Tecnos, Madrid, 1989. 
del Estado, sino de un principio metódico, o procedimental de legitimación de la legislación. "El contrato no es el concepto de una experiencia (real o posible). Es un concepto puramente racional, pero no teórico, sino práctico: un concepto normativo y crítico (o una idea normativa de la razón práctica). Significa el criterio para juzgar la legitimidad. Al igual que el imperativo categórico, la idea del contrato invita a un experimento mental, ... a reflexionar acerca de si un pueblo (una voluntad común) estaría de acuerdo en imponerse a sí mismo una ley tal. Dicho en un lenguaje actual: toda ley debe ser examinada desde el punto de vista de su aptitud para obtener un consenso general"8. No obstante el paralelismo señalado, el imperativo categórico no se puede comprender conforme al modelo contractualista, como se verá más adelante.

En la Metafisica de las Costumbres la Filosofía política adopta el sesgo eminentemente jurídico, que es característico del liberalismo, y queda subsumida bajo la Rechtslebre. Pero Kant se distancia sin embargo de la tradición liberal, tanto como de la escolástica, en cuanto rechaza la posible confusión de la política con la ética, y concibe en cambio el campo jurídicopolítico a la manera de Maquiavelo y de Hobbes, como funcionalmente autónomo de la moral. El primer "Apéndice" al escrito sobre La pazperpetua comienza con la aseveración solemne de que "no puede existir ninguna discrepancia entre la política como teoría del derecho aplicada y la teoría moral y, por consiguiente no puede haber conflicto entre la teoría y la práctica". Pero en lo que sigue, y en otros textos, se ocupa de advertir fuertemente que en el campo de lo político no es necesario ni posible, o por lo menos no es realista ni prudente, presuponer que los ciudadanos en cuanto tales, o los sujetos del derecho, sean de hecho también morales; ni es función del derecho y del Estado ejercer una coerción moralizante, o prescribir a los individuos cuál es su propio bien. Desde el punto de vista jurídico-político sólo es necesario que los ciudadanos se vean coaccionados a cumplir la ley, sin importar si lo hacen por interés, por oportunismo, o por convicción. El buen funcionamiento del ordenamiento jurídico y la paz social no pueden presuponer la virtud. Las leyes jurídicas y el juego de la política tienen que poder funcionar independientemente de la moral, mediante la fuerza o el respaldo de mecanismos como los controles recíprocos

${ }^{8}$ Höffe, O., Estudios sobre teoría del derecho y la justicia, Alfa, Barcelona, 1988, p. 26. 
de los propios actores, las sanciones previstas en el sistema jurídico, y la garantía de un poder estatal efectivo.

"Si bien el hombre no puede ser obligado a ser moralmente bueno, sí está obligado a ser un buen ciudadano. El problema del establecimiento del Estado tiene solución, incluso para un pueblo de demonios (aunque esto suene muy fuerte) siempre que tengan entendimiento... pues no se trata del perfeccionamiento moral del hombre, sino del mecanismo de la naturaleza"9.

Estas provocativas expresiones del gran filósofo de la moralidad son significativas de su fuerte rechazo de la moralización del derecho y de la política, y de su proximidad a los puntos de vista del realismo político, o de la Realpolitik. De hecho en los Estados existentes y relativamente bien ordenados las prácticas de los hombres respetan en buena medida las reglas del derecho pero, "con toda seguridad -agrega el autor- no es la moralidad la causa de este comportamiento, como tampoco lo es de la buena constitución del Estado, sino más bien al contrario, es de esta última que hay que esperar la formación moral de un pueblo" (Loc. cit., p. 39). En este punto Kant está de acuerdo con los antiguos y con Hegel y Marx: no es de la mera buena voluntad de los hombres, ni de la formación moral que cabe esperar la justicia de una sociedad bien ordenada, sino más bien a la inversa, por lo menos en términos generales, y en el estado actual del desarrollo de la moralidad. El realismo político no puede justificar sin embargo la adopción de máximas de acción incompatibles con los principios de la moral y del derecho por parte de los gobernantes y de los políticos, ni la subordinación de estos principios a fines políticos, o razones de Estado. Este es el delicado problema del que se ocupa el "Apéndice I" de La pazperpetua.

Pero la concordancia de Kant con la tradición de los autores mencionados es todavía más profunda, en cuanto pondrá de relieve también que el orden jurídico político justo es una condición necesaria, pero de ninguna manera la condición suficiente para que los hombres lleguen a ser morales, o para la existencia de la moralidad. Como se verá enseguida en el punto siguiente, Kant sostiene, en la línea de la tradición clásica de la

9 Kant, I., Zum ewigen Frieden, Akademie Textausgabe, ed. cit., VIII, 366; trad. esp. Sobre la pazperpetua, Tecnos, Madrid, 1991, p. 38. 
filosofía práctica, que hay otra condición social más directa y decisiva para tal fin, pero que no pasa ya por los canales de lo jurídico-político.

Antes de pasar a ese otro asunto que acabo de enunciar es necesario aludir aquí todavía al hecho de que también la realización del ideal cosmopolita es pensada en el opúsculo sobre La pazperpetua mediante el procedimiento de un contrato. Pero en este caso se trata ahora de la propuesta de un contrato real, histórico, en cuya dirección se han dado algunos pasos en los dos siglos posteriores a Kant, aunque siempre todavía muy insuficientes.

Los Estados con relaciones recíprocas entre sí no tienen otro medio según la razón para salir de la situación sin leyes que conduce a la guerra [o para salir del estado de naturaleza en las relaciones internacionales], que el de consentir leyes públicas coactivas, de la misma manera que los individuos entregaron su libertad salvaje (sin leyes), y formar un Estado de pueblos (civitas gentium)... que abarcaría finalmente a todos los pueblos de la tierra" ("Segundo Artículo definitivo para La pazperpetua) ${ }^{10}$.

\section{2. La comunidad ética}

En el escrito de 1793 sobre La religión dentro de los límites de la mera razón, se refiere Kant en su primera parte a la presencia de un principio del mal que, junto al bien, está arraigado en la propia naturaleza del hombre: el "mal radical". Después de tratar en la segunda parte la lucha del principio del bien con el mal en el hombre, se ocupa en la tercera de cuál es la condición necesaria para que el bien pueda triunfar. Voy a exponer aquí los conceptos fundamentales de la Sección Primera de esta Tercera Parte del libro.

El comienzo del texto indicado plantea en cierto modo una doble paradoja. Por un lado sostiene que la propensión al mal es innata e inextirpable $y$, en este sentido, se puede decir que "el hombre es por naturaleza malo"; por otro lado explica sin embargo que no es el hombre solitario, que vive aisladamente, el que se ve arrastrado por esta propensión al mal, sino que las circunstancias que despiertan la maldad en el hombre provienen de la vida social, aunque en un sentido bien diferente de Rousseau.

${ }^{10}$ Kant, I., ed. cit. VIII, p. 357; trad. esp., ed. cit., p. 25-26. 
"La envidia, el ansia de dominio, la codicia, y las inclinaciones hostiles que se derivan de todo ello, se apoderan de su naturaleza, en sí modesta, tan pronto como está entre [otros] bombres (wenn er unter Menschen ist); no es necesario presuponer tampoco que estos [los otros] están ya hundidos en el mal y constituyen ejemplos que inducen a él; basta que ellos estén ahí, que lo circunden, y que sean hombres (es ist genug, dass sie da sind, dass sie umgeben, und dass sie Menschen sind) para corromperse mutuamente en sus aptitudes morales, y hacerse malos unos a otros (sich einander böse $z^{u}$ machen)" (Relig.751-52; 11811).

La otra paradoja, que se suma a la anterior, es que el individuo sólo no puede tampoco dominar la propensión al mal en sus relaciones con los otros y, para mantener su fidelidad a "los deberes de virtud" necesita la ayuda, o el apoyo de una comunidad integrada con este fin moral. Es decir que el hombre aislado, fuera de la sociedad, no tiene cómo ser malo; pero si permanece sólo dentro de la sociedad, difícilmente puede ser bueno. Para el desarrollo de la moralidad en las relaciones con los otros el hombre tiene que asumir una identidad moral intersubjetivamente reconocida, como miembro de un nosotros. En el lenguaje de Kant esto es "una unión de hombres bajo meras leyes de virtud"12, a la cual se le ha de llamar: "una comunidad ética (ein ethisches gemeines Wesen)" (Relig. 751-752; 118).

Para explicar la necesidad de la formación de la comunidad ética se vale Kant de una analogía con la situación en que se encontrarían los hombres, según las descripción de Hobbes, si no existiera un ordenamiento jurídicopolítico y ningún poder soberano capaz de hacer respetar coactivamente las leyes civiles, el "status belli" de todos contra todos, que Kant precisa ahora

11 Relig. es la abreviatura de: I. Kant, Die Religion innerbalb der Grenzen der blossen Vermunft (Akademie Textausgabe, vol. VI). Los números de página entre paréntesis remiten, en primer lugar a la edición más corriente: I. Kant, Werkausgabe VIII, Suhrkamp, Frankfurt, 1991; y en segundo término a la traducción castellana: de F. Martínez Marzoa: I. Kant, Las Religión dentro de los límites de la Razón, Alianza, Madrid, 2001. La traducción de los textos citados ha sido revisada y corregida con el original alemán.

12 Las "leyes de virtud" son puramente morales, carecen de toda coactividad externa, social o jurídica; el respeto de las mismas hace a un hombre bueno, o virtuoso, así como el obrar conforme a las leyes jurídicas hacen de él un ciudadano correcto. 
como "estado de naturaleza jurídico". De manera semejante hay que pensar la situación de los hombres mientras no se integren al mismo tiempo en una comunidad ética de personas morales, como un "estado de naturaleza ético", en el cual los individuos están expuestos e indefensos frente al incesante ataque del principio del mal, y se transforman, a su vez, en sus instrumentos.

Las normas de la virtud de la comunidad "ética" deberían armonizar con las leyes jurídicas de la sociedad civil, pero son enteramente diferentes. Hay por lo menos cuatro propiedades fundamentales que hacen esta diferencia (cfr. Relig. 757; 127) ${ }^{13}$. 1) La universalidad de esta comunidad, que debe extenderse a todo el género humano, independientemente de la diversidad de opiniones contingentes. De hecho la extensión de la comunidad ética puede ser menor, o mayor que la de la sociedad civil, pero de acuerdo a su propio fin la idea de esta comunidad debe tender a una asociación universal de la humanidad en cuanto tal. 2) Los motivos de esta unión son puramente morales. Esta "pureza" de la intención implica que se prescinde aquí tanto de los fines empíricos, o de todo otro tipo de intereses, como de las exaltaciones del sentimiento o de la superstición ("Gereignit vom Blödsinn des Aberglaubens und dem Wabnsinn der Scbwärmerei”). 3) La libertad, tanto interna, en las relaciones de sus miembros entre sí, como externa, frente al poder público. Los individuos no se unen en esta comunidad, como en la sociedad civil, renunciando a su libertad con el fin de constituir un poder soberano que atemorice a todos y los proteja de peligros externos a ellos mismos. El tipo de coacción de las leyes de virtud es puramente interior. Además, la adhesión a una comunidad ética, y la permanencia en ella, deben ser siempre voluntarias. 4) La inmutabilidad de sus principios, que expresan obligaciones morales necesarias y que han de permanecer independientes de las previsiones contingentes de toda organización conforme a las circunstancias cambiantes de tiempo y lugar. El Prefacio a la $1^{\text {a }}$ edición de La Religión comienza con el recuerdo de que: "La moral se funda en una

${ }^{13}$ En el desarrollo ulterior del concepto de comunidad los textos kantianos que son objetos de este estudio mezclan estas determinaciones conceptuales con sobredeterminaciones derivadas de los conceptos de la religión dentro de los límites de la mera razón, de la fe racional pura, y con la crítica de las iglesias estatutarias que se basan en creencias históricas particulares. En esta exposición se prescinde de esos aspectos que deberían ser objeto de una discusión más bien teológica y de historia de la religión. 
concepción del hombre como ser libre que, a través de la razón, se obliga sí mismo por medio de leyes incondicionales [y puede hacerlo precisamente porque es libre y racional] (Relig. 649; 21).

Quiero dejar abierta aquí una línea de pensamiento que se desprende, o se inspira en las determinaciones kantianas precedentes. Los motivos que mueven a los hombres a la unión en la comunidad ética de las personas morales en cuanto tales, y al respeto de las "leyes de virtud", no se pueden desenmascarar como la internalización del temor a una posible sanción externa, sino que se tienen que interpretar más bien como la manifestación del deseo de pertenencia y de fidelidad a las promesas recíprocas de ser morales. La única penalidad que se sigue del apartamiento de las "leyes de virtud" es la autoexclusión de la comunidad ética, la pérdida de la amistad, porque quien es inmoral no es confiable y no puede tener amigos; no ama ni puede ser amado. Pero lógicamente, sólo sufre esta exclusión como pena quien desea y ha decidido pertenecer a la comunidad ética. En tal sentido puede hablarse con Tugendhat de una decisión que está en el origen de la moralidad. Este momento decisionista no se comprende sin embargo sin el deseo de pertenencia, o de unión moral, y el juicio de valor sobre la pertenencia a esta comunidad.

La relación entre la comunidad ética y el orden jurídico-político del Estado es, según hemos visto, al mismo tiempo de inclusión de la primera en la segunda, y de entera autonomía, como la separación de la Iglesia y del Estado. La comunidad ética no podría existir sin la protección y la garantía del derecho, pero tampoco sin su independencia frente al poder político. Parece que esta relación será fuente de inevitables tensiones y conflictos, sobre todo si tenemos en cuenta, en primer lugar, que la comunidad ética es una asociación voluntaria pero no meramente privada, como la familia, sino que su constitución y sus normas han de ser públicas, reconocidas por todos sus miembros y expuestas a la luz pública de la sociedad civil. Y en segundo lugar, es preciso tener en cuenta que esta comunidad está inscripta dentro del Estado pero, a su vez, por su misma naturaleza, lo trasciende y tiende a adquirir un alcance universal, o cosmopolita, lo cual incremente su poder espiritual frente al poder político. Si bien el propio Kant no explicita aquí estas consecuencias polémicas en su contexto (hay que recordar que el texto tuvo bastantes dificultades con la censura), debemos presuponer que él no era inocente sobre las limitaciones a la soberanía que implicaba su doctrina y que lo ponía en este punto en las antípodas del absolutismo hobbesiano. 
La significación de este concepto de una comunidad ética sostenida solamente por la voluntad autónoma de mantener las promesas recíprocas de fidelidad a los principios de la moralidad (sin garantías institucionales o jurídicas), apoyada en la identidad moral de sus miembros, e independiente de la estructura jurídico-política del Estado, se redescubre y se puede valorar más adecuadamente recién ahora, en el contexto de los debates actuales de la filosofía política, a partir de la declinación del modelo del Estado moderno, del progresivo descentramiento de la institucionalidad política en la sociedad actual y del retorno de la sociedad civil, o de la recuperación de su autonomía ${ }^{14}$.

La comunidad ética, constituida por la voluntad autónoma de mantener las promesas recíprocas de fidelidad a los principios de la moralidad (sin garantías institucionales o jurídicas), y apoyada solamente en la identidad moral de sus miembros, no es para Kant una mera idea, sino algo que es ya real y existente de algún modo en la sociedad civil; pero aclara sin embargo que "un conjunto de hombre unidos con esta intención moral [es decir: una pequeña comunidad de amigos morales] no puede considerarse todavía como la comunidad ética misma, sino como una asociación particular", que se orienta en el sentido de dicha comunidad, y que puede estar abierta y en conexión con otras asociaciones del mismo género, pero a su realidad les falta todavía la nota esencial de la universalidad. Han existido siempre muchas comunidades éticas particulares, sin las cuales los individuos no podrian ser morales, pero la idea regulativa conforme a la cual se constituyen estas comunidades de amigos morales, o el telos al que debe orientarse su obrar, es para Kant la comunidad ética universal del género humano. Y habría que agregar todavía que, sin esta apertura universalista, las comunidades particulares cerradas sobre sí mismas pierden incluso todo sentido moral. La realización de las comunidades éticas particulares es incluso siempre precaria en el contexto de un entorno social que vive en estado de naturaleza ético. Ahora bien, el principio de la realización de este sentido universal no tiene su fuente en la facticidad, o en la historicidad del origen de estas comunidades particulares y en sus tradiciones, sino en el descubrimiento, o la revelación, del nivel más profundo de la moralidad.

${ }^{14}$ Mientras escribía estas páginas me ha llegado el anuncio de la aparición de un libro colectivo sobre el mismo tema que no he podido consultar: Michael Städtler (Herausgeber), Kants "Ethisches Gemeinwesen", Akademie Verlag, Berlin, 2005. 


\section{E1 universalismo de la Moralidad}

El principio de la moralidad se ubica en un "metanivel"15 con relación a la experiencia de la vida moral y a las prácticas e instituciones sociales. En el lenguaje de Kant, se trata de un nivel de reflexión metafisica. Metaphysik der Sitten. La traducción de Sitten por "costumbres" es quizás la mejor que se ha podido hacer en nuestra lengua. Pero ésta no es, sin embargo, una buena traducción, porque la palabra "costumbre" carece de las resonancias axiológicas del vocablo original y de sus derivados. Con los adjetivos sittlich/unsittlich se atribuyen en alemán a una conducta, y al sujeto de la misma, calificativos fuertes que pueden traducirse como bonesto/deshonesto, o decente y su contrario. Kant aclara de esta manera el nombre que ha elegido para el título de sus obras sistemáticas de Ética: "la palabra alemana "Sitten" significa maneras y formas de vida" (MdS, Ak. Ausg, 216), es decir: la "ética" de una comunidad. Este es precisamente el sentido de la palabra griega ethos, de donde procede la Ética según lo explica Aristóteles en el Libro II, Cap. 1 de la Ética a Nicómaco. Y dado que ya que la palabra griega "etbos" se usa hoy de manera corriente en la literatura filosófica, podríamos traducir entonces el título de los libros kantianos en un lenguaje filosófico más contemporáneo, como "Metafísica del etbos", y no de las meras "costumbres".

Hay que tener en cuenta todavía sin embargo el significado especial, para nada ontológico, de la palabra "metafísica" en el lenguaje kantiano, que alude en cambio a una "filosofía pura", en cuanto referida en este caso a las reglas o leyes a priori de la libertad. En tal sentido me gustaría proponer para nosotros una versión más libre, con sabor wittgensteiniano, del título de Kant, porque lo que el filósofo se proponía hacer, y lo ha hecho de manera magistral, es explicitar lo que podríamos llamar hoy: La gramática profunda del ethos ${ }^{16}$. Esta expresión me parece apropiada sobre todo para la Grundlegung, que se mantiene efectivamente en el nivel más formal de la gramática universal del ethos, e incluso nos dice de manera explícita y reiterada a lo largo del texto que es eso precisamente lo que está haciendo, a

${ }^{15}$ Cfr. H. Putnam, El desplome de la dicotomía becho-valor, Barcelona 2004, p. 136 y ss. ${ }^{16}$ En Los Progresos de la Metafísica el propio Kant se refiere a la ontología crítica como "una gramática de la experiencia" (Ak. Ausg. XX, 260). Debo esta indicación a Marcos Thisted. 
saber: buscar una formulación reflexiva, o la reconstrucción racional de los principios de la razón pura práctica, los cuales se encuentran siempre ya operantes en la razón práctica común humana, o en el ethos de las diferentes culturas, como nos gustaría decir hoy.

Bastan estas simples aclaraciones para desbaratar las críticas tan en boga en cierta literatura que se representa el imperativo categórico como una forma represiva o empobrecedora de la vida moral $i E s$ como si se reprochara a la gramática que sus reglas no contengan ya toda la literatura! Es claro que en el ethos, en los valores, tradiciones y costumbres, hay mucho más, una riqueza de contenidos peculiares de la forma de vida de cada grupo humano, frente a lo cual los enunciados formales de la moralidad kantiana tienen que aparecer como una "ética mínima"17.

La relación entre este nivel "metafísico" de la filosofía práctica y la "ética" del Lebenswelt ha sido graficada por Kant mediante la imagen de los círculos concéntricos. El "Prólogo a la $2^{2}$ edición de La religión dentro de los limites de la mera razón comienza con una aclaración acerca del título del libro, el cual había dado lugar a interpretaciones malintencionadas que lo leían como una ambigüedad encubridora de la intención de reemplazar la religión, o la fe, por la mera razón. Si esa es una lectura posible, no es la del propio autor que, con ese título, había querido marcar los límites de la razón, o de la comprensión filosófica frente a la significación del relato de los libros sagrados. Esta aclaración vale también del mismo modo para la relación de la eticidad histórica con la moralidad pura. Mientras que la primera puede comprender en sí al menos también a la segunda,

...esta última en cambio, a la inversa, no puede contener lo histórico de la primera; puedo considerar por lo tanto a la una como una esfera más amplia de la fe [y de lo ético], que encierra en sí a la otra [la religión racional y la moralidad pura] como una esfera más estrecha (no como dos círculos exteriores el uno al otro, sino como concéntricos). El filósofo en cuanto maestro de la pura razón (als reiner Vermunftlebrer) debe mantenerse dentro de los límites del círculo [interior] más estrecho (a partir de meros principios a prior), y para esto ha de hacer abstracción de todas las experiencias [de la vida ética y religiosa]" (Relig. 659; 31 ).

${ }^{17}$ Cfr. Adela Cortina, Ética minima, Tecnos, Madrid, 1986. 
Se podría representar también el núcleo metafísico del ethos de las comunidades, y los principios morales que puede explicitar la filosofía en la Ética minima universal, como la escueta y descarnada estructura ósea del esqueleto que sostiene desde dentro la carne y las bellas formas del cuerpo humano. La metáfora del esqueleto me parece significativa para representar las relaciones de la "ética" y la moral, porque la moralidad universalista se ha comprendido a veces como un corsé impuesto desde fuera a la vida "ética" por una racionalidad abstracta que niega o reprime las diferencias. El método de Kant no es, sin embargo, un construccionismo racionalista, sino un procedimiento reconstructivo que busca explicitar y fundar los principios básicos de la moralidad que es interior a las experiencias de la vida buena y del ethos vivido, como las condiciones normativas que hacen posible la existencia de toda comunidad "ética", o como la gramática universal de la interacción humana en cuanto regida por una razón común que se reconoce en este momento de incondicionalidad del respeto de la humanidad en todas las personas.

Si nos atenemos a la Grundlegung, o Fundación de la gramática profunda del ethos, la Ética de Kant no pretende prescribir qué debemos hacer, sino cómo debemos obrar y tratar a los demás, cualquiera sean los fines que nosotros nos proponemos en nuestras acciones. En este sentido es una Etica formal, porque tiene en cuenta que hay una innumerable diversidad de fines valiosos que los hombres pueden proponerse en su vida, y Kant pretende mostrar que, si bien el contenido y los fines de las acciones humanas no son moralmente irrelevantes (como a veces se ha interpretado de manera incorrecta), lo que es formalmente decisivo para la calificación moral de las acciones y de las personas no es el contenido material de lo que hacen, no son sus actividades y formas de vida (profesiones, costumbres, valores culturales, etc.) ni el éxito de sus propósitos, sino "la buena voluntad", que no es por cierto la mera "buena intención". El principio moral debe interpretarse como un criterio universal para juzgar la moralidad intrínseca de las máximas que guían nuestras acciones (cualquiera sea su materia), y manda directamente una forma de obrar, con independencia de los fines, es decir: "sin condicionar esta conducta al logro de ningún otro propósito". Y es precisamente por esta libertad incondicionada frente a todos los fines externos a la moralidad misma que esta ley tiene la forma de un imperativo categórico y no meramente hipotético. 
Conforme a la primera formulación kantiana del imperativo categórico, el criterio de la moralidad de las máximas por las que se rige la conducta es la universalizabilidad. Empleo esta palabra porque las ley moral no manda en principio universalizar de hecho determinadas reglas, por ejemplo las máximas de nuestra propia conducta, sino reflexionar sobre la posibilidad de que una máxima se convierta en ley universal (es decir, si sería posible su funcionamiento como regla universal) y sobre la aceptabilidad de esta perspectiva para el propio sujeto de la acción. El deber moral implica la conciencia de una auto-obligación, que el sujeto tiene que aceptar por sí mismo, porque se lo impone su propia razón y voluntad autónomas y se conecta con su identidad esencial como ser racional.

El examen de la universalizabilidad de sus máximas es un test que cada uno debe hacer al mismo tiempo de manera autónoma en su propia conciencia, pero lleva implícita la idea de reciprocidad y de intersubjetividad. Se trata por lo tanto de un principio de justicia. Si reflexionamos sobre lo que hacemos cuando obramos mal -advierte Kant, "nos daremos cuenta de que en realidad no podemos querer que nuestra máxima sea seguida por todos como una ley universal, sino más bien al contrario", porque la ventaja está en transgredir una ley mientras los demás la respetan. La inmoralidad consiste entonces en exceptuarme a mí mismo (para mi propio provecho) del cumplimiento de una ley general, y adoptar una forma de obrar que no podría admitirles a todos los demás. Las máximas conllevan el contenido concreto de valores y actitudes de la vida "ética" de la comunidad de pertenencia, y responden a los problemas particulares de cada contexto de acción. Puede haber incluso una pluralidad de máximas diferentes para el mismo campo de acción, que aprueban el test de la universalizabilidad. Esta no es una deficiencia, como se ha pensado desde Hegel, sino una muestra de la amplitud y el pluralismo del criterio kantiano de la moralidad.

$\mathrm{El}$ principio universal de la moralidad no es puramente formal, sino que tiene un contenido universal, el cual está explicitado en la segunda formulación de Kant, que enuncia el deber incondicionado de tratar a la humanidad, es decir, a la persona humana en cuanto tal, tanto en uno mismo como en todos los demás, siempre como fin y nunca como mero medio. La segunda fórmula explicita con esto también el modo cómo debe entenderse la primera, es decir, que debo observar el principio de la reciprocidad simétrica de las reglas del comportamiento por sí mismas, porque es lo justo, y no de manera meramente instrumental, o estratégica, 
para mi propia seguridad. El mandato moral de no instrumentalizar a nadie en función de mis propios fines implica al mismo tiempo la descalificación de toda comprensión instrumental de la propia moral.

El respeto de la persona humana en cuanto tal y como fin en sí misma, o auto-fin, es el verdadero fundamento del universalismo moral, por cuanto esta propiedad de ser persona y fin en sí mismo, de ser-para-sí, y no para-otro, o de-otro, es una propiedad que le compete por igual a todo ser humano en cuanto ser racional, independientemente del color de su piel o de su posición social, de sus cualidades físicas o intelectuales, de su manera de vivir o de su cultura, etc. Tratar a toda persona como fin en sí mismo quiere decir considerarla como sujeto de los propios fines que ella se propone en su libertad. No como otro objeto de mi conocimiento y acción, sino como otro sujeto, que es el centro de su propio mundo. Esta forma de relacionarme con el otro, como otro sujeto autónomo, exige un descentramiento de las perspectivas del propio yo, y una apertura del egocentrismo natural. Esta apertura, o esta amplitud de pensamiento que es capaz de ponerse en el lugar de cualquier otro, como lo dirá Kant en la Crítica del Juicio, está en la base, no sólo de la moralidad, sino de toda la intersubjetividad humana.

$\mathrm{Si}$ nos atenemos a la Grundlegung puede parecer que en la Ética kantiana se trata solamente de la simetría y la reciprocidad de lo permitido y $l o$ probibido, no de obligaciones morales positivas. La lectura de la Metafísica de las costumbres puede producir en cambio la impresión de un retorno al tipo de moral tradicional, concretista y prescriptiva. Allí hablará Kant de las máximas que son obligatorias. Pero estas no pueden derivarse directamente de la primera fórmula del imperativo, sino a través de la segunda, que manda tratar a la humanidad en todas las acciones como fin y no como mero medio. De este fin se desprenden todos los otros fines de la razón pura práctica. La idea de un fin que es un deber objetivo implica mandatos morales positivos. $Y$ toda "la Ética puede definirse también como el sistema de los fines de la razón pura práctica" ( $M d S, 231)$. El tomar en serio el carácter de fin en sí misma de la humanidad, en general y en cada persona singular, conlleva como escribe A. Cortina, no solamente limitaciones o restricciones para mi 
libertad, sino también una tarea a realizar, un deber positivo de humanidad ${ }^{18}$.

\section{Moral y juicio crítico}

"Del hecho que la regla formal [de la moralidad] se aplica a una multiplicidad de máximas [tomadas de la experiencia de la vida moral] resulta precisamente una multiplicidad de deberes que responden a una diversidad de situaciones. Se hace emerger así una cierta productividad del juicio moral"19. Está claro que sin los fines e intereses, y sin la multiplicidad de las máximas que orientan de hecho la vida y configuran el carácter y la identidad de los hombres concretos en la historia, la tarea crítica de la razón práctica se habría anulado a sí misma porque no habría dejado nada que someter a su juicio crítico y "la regla de universalización sería, por así decirlo, como un molino que no tiene nada que moler".

Finalmente, el movimiento ascendente de subsunción de la máxima en la regla de universalización tiene que ser complementado, como bien lo ha señalado Ricoeur (loc. cit.), con el movimiento descendente del juicio en el contexto de acción, y de la aplicación de las máximas generales al caso particular que, en los casos difíciles (los bard cases con que se enfrentan los jueces, en la terminología de R. Dworkin) presupone un doble trabajo bermenéutico: 1) la interpretación contextualizada de la acción posible $y$ razonable; 2) la reinterpretación de las propias máximas, o normas de contenido concreto, a la luz del contexto de aplicación. La toma de decisiones requiere siempre la evaluación de las circunstancias de la acción, de sus posibles consecuencias, y la revisión de la propia norma en confrontación con las situaciones no previstas por ella. Doble hermenéutica que no podía ser objeto de una "Metafísica del ethos", pero tampoco ha sido adecuadamente considerada en la Crítica de la Razón Práctica. La pregunta que quiero formular en este último punto de mi exposición es, si esta laguna de los textos éticos kantianos no se puede completar mediante la ampliación de los alcances de la doctrina del juicio reflexivo del gusto estético de la primera

${ }^{18}$ Cfr. A. Cortina, "El comunitarismo universalista de la filosofía kantiana", en J. C. Cordón, Moral, Derecho y politica en I. Kant, Cuenca, 1999, pp. 241-252.

${ }^{19}$ Ricoeur, P., Soi-même comme un autre, París, 1990; Si mismo como otro, FCE, México, 1996, p. 286-287. 
parte de la Tercera Crítica, la cual me parece relevante, no para la fundación del principio de la moralidad, pero sí para su aplicación, es decir: para la vida moral ${ }^{20}$. Voy a aducir aquí solamente dos indicios textuales positivos, que me parecen suficientes para mostrar que la ampliación propuesta podría considerarse como un desarrollo actual de la filosofía de Kant; o que no sería, por lo menos, un programa antikantiano, o ajeno al espíritu de esta filosofía.

En el "Prefacio" de la Grundlgung hace jugar Kant la diferencia entre dos partes de la Ética. a) "La parte pura", que explica el fundamento de la obligación (der Grund der Verbindlichkeit) y de toda la filosofía moral, la cual "no puede apoyarse en principios de la mera experiencia", sino que "se apoya enteramente en la parte pura" (alle Moralpbilosopbie berubt gänzlich auf ibrem reinen Teil'. b) La parte "aplicada al hombre" (auf den Menschen angewandt) se tiene que orientar en cambio mediante la experiencia, teniendo en cuenta las circunstancias concretas y cambiantes de la aplicación de las leyes morales. Este segundo paso, de la aplicación del principio de la moralidad y de las máximas, o del pasaje a la acción moral, "exige por cierto todavía una capacidad de discernimiento, aguzada mediante la experiencia (durch Erfabrung geschärfte Urteilskraft)"21. Esta división de la Filosofía moral kantiana, que determina la estructura de la Crítica de la razón práctica, como veremos enseguida, y la significación de la segunda parte, han sido poco destacadas por los expositores, e ignoradas por sus críticos.

Si tomamos en serio los términos precisos empleados por el autor en el texto, resulta claro que no se trata del mero enjuiciamiento (Beurteilung) del moralista, o predicador moral, ni de los prejuicios del moralismo convencional, sino de la capacidad reflexiva de juzgar, o de discernimiento (como se ha retraducido, con mayor precisión el título de la Kritik der Urteilskraft). Debe decirse que esto es tan importante como la cuestión

20 Para una exposición más desarrollada de la doctrina del juicio reflexivo, y su ampliación al campo de la política, cfr.: J. De Zan, "Amplitud de pensamiento y capacidad de juzgar. La lectura de H. Arendt de la Crítica del Juicio", en RPF (Revista Portuguesa de Filosofia), Vol. sobre La berencia de Kant, por aparecer, Braga, 2005.

${ }^{21}$ Kant, I., Akademie Textausgabe, ed. cit., IV 389; trad. española de M. G. Morente, Fundamentación de la métafísica de las Costumbres, Espasa Calpe, Madrid, 1946, p. 18-19. 
teórica de la fundamentación, porque en el juicio se juega lo verdaderamente decisivo (en sentido literal). Para ilustrar estas aseveraciones basta rememorar los libros de Hannah Arendt Sobre los orígenes del totalitarismo y El Juicio a Eichman en Jerusalén, en los que se pone en evidencia como toda una sociedad, incluyendo a sus grandes filósofos, puede llegar a perder enteramente, con escasas excepciones, esta capacidad de juicio, o de discernimiento entre el bien $y$ el mal, como fue el caso de la sociedad y de la cultura alemana bajo el nacional-socialismo de Hitler.

Esta exigencia que plantea a la Urteilskraft la aplicación de las leyes morales (este plural engloba el imperativo categórico y las máximas apoyadas en el test de la universalizabilidad) se explica en el texto kantiano por dos razones: 1) "en parte para diferenciar en qué casos tienen su aplicación $y, 2$ ) en parte para lograr que las leyes morales puedan tener acceso en la voluntad de los hombres con el vigor para ponerlas en práctica (Eingang in den Willen des Menschen und Nacbdruck zur Ausübung zu verschaffen), dado que estos... no pueden tan fácilmente hacerlas eficaces in concreto en las circunstancias cambiantes de su vida (in seinen Lebenswandel)" (loc. cit en nota 19). A esta segunda razón de la necesidad de un ejercicio reflexivo del juicio moral va a dedicar Kant específicamente toda la Segunda Parte de la Crítica de la Razón Práctica.

Con respecto a la razón 1) es preciso observar que, a diferencia del juicio estético del gusto, el juicio moral se apoya en una ley objetiva, a priori, pero esta ley no se aplica directamente a las decisiones y a las acciones, sino a las máximas que las orientan, las cuales se mantienen, a su vez, todavía, en un nivel de generalidad. Yo puedo haber testeado la moralidad de una máxima conforme al criterio de la universalizabilidad, pero debo justificar todavía en cada contexto mi decisión y mi acción conforme a dicha máxima. Este pasaje no puede realizarse mediante la lógica de la subsunción del juicio determinante. La especial exigencia planteada a la Urteilskraft, de la que habla el texto de la Grundlegung, tiene que interpretarse entonces en el sentido del juicio reflexivo de la Tercera Crítica.

Con respecto a la razón 2) sobre el papel de la Urteilskraft en la Ética, quiero evocar ahora el mencionado texto de la breve "Segunda Parte" de la 
Crítica de la Razón Práctica ${ }^{22}$. Toda esta parte está dedicada precisamente a explicar cómo el ejercicio de la capacidad de juicio mediante el análisis de casos, y la confrontación de las interpretaciones y valoraciones de los casos analizados a través de un debate, o diálogo argumentativo, es el método adecuado para el desarrollo de la capacidad de discernimiento reflexivo, o para la formación del juicio moral crítico, y del sentimiento moral subjetivo. No se trata solamente de un ejercicio escolar, sino del cultivo del interés de la razón en el desarrollo de la capacidad de discernimiento y de la buena disposición, o actitud moral "como los motores (Triebfedern) de la acción". Esta práctica puede comenzar "como un juego del juicio (als ein Spiel der Urteilskraft), en el cual los niños pueden rivalizar entre sí” (Op. cit. p. 154). Pero dicho juego se transforma en algo serio en cuanto contribuye a formar el hábito de la reflexión moral crítica "y deja impresos de manera duradera tanto el sentimiento de admiración y respeto [de las buenas acciones] como el desprecio o la repulsión" de la maldad, de modo que este discernimiento "venga a ser natural ocupación que acompañe todas nuestras acciones". Esta práctica hace crecer además el sentimiento moral duradero de la estima, "no sólo de la corrección de la acción, sino también del valor moral como intención" y el sentimiento de reproche o desaprobación de las acciones que han merecido el juicio negativo de la razón. Esto constituye por sí mismo "una buena base para la probidad de toda la vida". El procedimiento para la pedagogía moral recomendado por Kant, que consiste en la confrontación de argumentos de aprobación y de censura moral de casos reales, o posibles, no debería interpretarse como un mero ejercicio didáctico para la clase de Ética del colegio, sino como un entrenamiento para la aplicación del procedimiento intersubjetivo del juicio moral en las situaciones reales de la vida humana.

${ }^{22}$ El título de esta Segunda Parte: "Metodología de la razón pura práctica" puede ser engañoso, pero Kant aclara su significado en el primer párrafo con las mismas expresiones del texto citado de la Grundlegung. "Unter dieser Methodenlebre [wird] die Art verstanden, wie man den Gesätzen der reinen praktischen Vernunft Eingang in das menschliche Gemüt, Einfluss auf die Maximen derselben $z^{u}$ verschaffen, d. i. die objektiv praktische Vernunft auch sujektiv praktisch machen können" (Ed. cit. V, p. 152). 


\title{
Resumen
}

Este artículo plantea (1) el problema de la fundamentación de la ética en la situación del pluralismo de la sociedad moderna y contemporánea. Se analizan luego (2) dos tipos de respuesta a este problema: el comunitarismo como la ética identitaria de un nosotros, y el contractualismo como la ética de los intereses de los socios, los cuales se presentan como teorías rivales frente al universalismo de la moralidad kantiana. Se muestra sin embargo (3) cómo el propio Kant había trabajado ya en distintos planos de la integración humana con los dos modelos del contrato social y de la comunidad ética, y los había articulado en su sistema. El principio universal de la moralidad (4) se ubica en cambio en el meta-nivel de la gramática profunda del ethos de las comunidades y de los contratos (Metaphysik der Sitten). Se observa finalmente (5) que los textos éticos fundamentales de Kant no han tratado de manera explícita el problema hermenéutico del juicio moral en los contextos de acción. Se analizan no obstante algunos pasajes de la Grundlegung y la Segunda Parte de la Crítica de la Razón Práctica, en los que hay indicaciones precisas sobre este problema. Se sostiene que la observada laguna se puede sortear mediante la ampliación de los alcances de la doctrina del juicio reflexivo del gusto estético de la primera parte de la Tercera Crítica, la cual parece relevante, no para la fundación del principio de la moralidad, pero sí para su aplicación, es decir: para la vida moral.

Palabras clave: "Kant", "universalismo / particularismo", "pluralismo", "moralidad"

\begin{abstract}
This article raises (1) the issue of the foundation of ethics in the situation of the pluralism of modern and contemporary society. Then (2), two types of answers to these problems are analyzed: comunitarism as the identitary ethics of an 'ourselves', and contractualism as the ethics of the partners' interests, which present themselves as rival theories in opposition to the universalism of kantian morality. It is however shown (3), how Kant himself had already worked at different levels of human integration with both models: that of social contract and that of ethical community, and had articulated them in his system. The universal principle of morality (4), on the other hand, places itself at the meta-level of the profound grammar of the ethos of communities and contracts (Metaphysik der Sitten). Finally, it is observed (5) that Kant's fundamental ethical texts have not explicitly dealt with the hermeneutical problem of moral judgment in contexts of action. However, some passages of the Grundlegung are analyzed, as well as the Second Part of the Critique of Practical Reason, in which we find precise indications on this issue. It is maintained, that the observed lack of treatment may be bridged by means of widening the scope of the doctrine of
\end{abstract}


reflexive judgment of aesthetic taste of the Third Critique's first part, which appears relevant, not for the foundation of the principle of morality, but for its application, i.e., for moral life.

Key words. "Kant", "universalism / particularism", "pluralism", “morality" 